\title{
Apuntes sobre la noción de espectralidad en la filosofía derrideana
}

\section{(4) Gabriela Balcarce}

CONICET-Universidad de Buenos Aires, Argentina

\begin{abstract}
Resumen
El presente artículo intenta explicitar algunos de los usos de la noción de espectro en la filosofía derrideana. Desestabilización del umbral entre la vida y la muerte, crítica a la metafísica de la presencia y al tratamiento humanista de la alteridad en el pensamiento de Lévinas anclado en la figura del rostro, así como también deconstrucción de cierta herencia del espíritu y con ello, de una concepción de la historia y la política idealista. Por último, la figura del espectro permitiría una articulación no dialéctica de las aporías derrideanas planteadas en los últimos años.
\end{abstract}

\begin{abstract}
This article tries to explain some of the uses of the notion of specter in the Derridean philosophy. Destabilization of the threshold between life and death, critical to the metaphysics of presence and the treatment humanist of otherness in the thought of Lévinas anchored in the figure of the face, as well as also a deconstruction of some inheritance of the spirit and with it, a conception of history and the idealistic politics. Finally, the figure of the specter would allow no dialectic articulation of Derridean's aporetics raised in recent years.
\end{abstract}

I. En 1993 Derrida presenta una conferencia que tendrá alto impacto en los círculos de discusión teórica marxista. En apertura del coloquio "Whitermarxism?" en la Universidad de Riverside, California, propone una manera de la pensar la presencia del marxismo en nuestros días a partir de una figura peculiar, a saber, la del espectro. Esta figura es sumamente plástica a la hora de ser empleada en el registro filosófico.

Desestabilización del umbral entre la vida y la muerte, crítica a la metafísica de la presencia y al tratamiento humanista de la alteridad en el pensamiento de Lévinas anclado en la figura del rostro, así como también deconstrucción de cierta herencia del espíritu y con ello, de una concepción de la historia y la política idealista. Por último, la figura del espectro permitiría una articulación no dialéctica de las aporías derrideanas planteadas en los últimos años.

\section{Palabras clave}

espectro deconstrucción aporía

Keywords

specter deconstruction aporetic 
1. En el citado de la obra derrideana se indicará primero la edición francesa y luego la traducción al castellano.
En el presente trabajo intentaremos elucidar algunos de los usos derrideanos de esta noción, a efectos de resaltar el valor contemporáneo de la misma en el terreno filosófico.

II. Como señala Cragnolini, el espectro "desafía la lógica de la presencia y de la identificación". En este sentido, resiste a la ontologización: "no habita, no reside, sino que asedia" (Cragnolini, 2007: 50). El escamoteo fenomenológico se corresponde con un presente "out of joint" (fuera de quicio), con una temporalidad que se abre en su mismo presentarse, desafiando toda lógica de la reunión, de la Versammlung:

\begin{abstract}
Mantener unido lo que no se mantiene unido, y la disparidad misma, la misma disparidad -volveremos constantemente a ello como a la espectralidad del espectro- es algo que sólo puede ser pensado en un tiempo de presente dislocado, en la juntura de un tiempo radicalmente dis-yunto, sin conjunción asegurada. No un tiempo de junturas negadas, quebradas, maltratadas, en disfunción, desajustadas, según un dys de oposición negativa y de disyunción dialéctica, sino un tiempo sin juntura asegurada ni conjunción determinable. Lo que vale que aquí se dice del tiempo vale también [...] para la historia [...]: "The time is out of joint", el tiempo está desarticulado, descoyuntado, desencajado, dislocado, el tiempo está trastocado, acosado y trastornado, desquiciado, a la vez que desarreglado y loco (Derrida, 1993: 41-4/31). ${ }^{1}$
\end{abstract}

"Out ofjoint": las posibles traducciones nos acercan al espectro poniendo en evidencia la lógica del asedio. Por un lado, "acosado", pero también y mayoritariamente, "desarticulado", "descoyuntado", "desquiciado", "desarreglado", "dislocado". Apertura a la fantología (discurso acerca del fantasma), es decir, a un más-que-ontología, si pensamos la ontología como el discurso acerca de los modos de ser de lo presente que vienen a la presencia. La figura del espectro entonces viene a inaugurar un nuevo espacio de apertura en la ontología como experiencia de lo imposible. Desentraña la intempestividad "desde una 'disyunción' de la presencia misma del presente" (Cragnolini, 2007: 51). Como señala De Peretti, el espectro es siempre un (re) aparecido, "un revenant, alguien que empieza siempre por volver, por regresar a contratiempo, cuando menos se lo espera o cuando no se lo espera en absoluto" (De Peretti, 2003: 29). La figura del espectro también puede ser pensada como una desestabilización del umbral entre la vida y la muerte, a través de la apelación en las primeras páginas de Espectros de Marx en torno a la aparición del fantasma de Hamlet. "Jura", afirma el fantasma, antes de cualquier instante de reconocimiento bajo una cierta "lógica de la visitación". Una exigencia de afirmación de la alteridad, una respuesta ante la precedencia del espectro que no confirma la ipseidad de quien es interpelado, antes bien, el efecto visera impide la tradicional lógica del reconocimiento, allí donde el espectro nos mira sin que podamos mirarlo. Un pedido de disposición y entrega que se corresponde con la exigencia de respeto a la alteridad derrideana enmarcada en un futuro anterior. En este sentido, el espectro constituye una crítica al tratamiento humanista de la alteridad en el pensamiento de Lévinas anclado en la figura del rostro. El "efecto visera" impide la percepción de otro-sí-mismo, en continuación con la estela fenomenológica husserliana presente en la quinta meditación cartesiana.

Anterioridad, desproporción, disimetría, el espectro rompe los umbrales de la constatación subjetiva moderna, del rodeo de la subjetividad que pasa por el otro para volver a sí. Porque el espectro, lejos de confirmarnos, nos aleja de la certeza.

III.La desestabilización del umbral entre la vida y la muerte nos acerca, asimismo, a la noción de "duelo infinito" (Derrida, 1988). A partir de la muerte de Paul de Man, Derrida encomienda unas páginas a su memoria, Mémoires: Pour Paulde Man. Sin embargo, estas memorias, que constituyen el duelo, se desplazan de lo que 
representaría una concepción clásica del mismo, si por ello mentamos al duelo como la presencia del otro, del otro que ya no está presente en el modo de la presencia, a partir del recuerdo. El duelo en este sentido es el recuerdo del otro en mí, la memoria del otro a la cual debo atender, tematizar, interiorizar: el duelo es la interiorización del otro, ya muerto, no presente (Cragnolini, 2007: 104 y ss.). Recordemos algunas de las páginas de Duelo y melancolía (Freud, 1997), donde el pensador austríaco describe el proceso de un duelo exitoso a partir de la redistribución de la libido desligándonos así del objeto perdido para de ese modo "volver a quedar libre el yo y exento de toda inhibición". En este sentido entonces, el duelo sería el proceso por el cual el otro, la otredad que significa el objeto perdido, es absorbida y neutralizada por el yo, redireccionando su energía libidinal. De este modo, la situación del duelo se presenta como un proceso que tiene como finalidad la localización del muerto para introyectarlo y así, retornar a la mismidad redistribuyendo la libido en nuevas situaciones y/o objetos.

Derrida propone, sin embargo otra figura del duelo, una figura que no responde a la de una absorción, inclusión del otro en la mismidad, bajo la forma de la interiorización. El filósofo propone la figura del duelo imposible, ${ }^{2}$ es decir, la de un duelo infinito, que se resiste a los intentos de fagocitación de la mismidad, ligado a una concepción de la memoria efectual, esto es, una memoria que no coincide con un mero receptáculo de recuerdos pasados y almacenados allí:

Este ser "en nosotros", el ser "en nosotros" del otro, en acongojada memoria, no puede ser ni la llamada resurrección del otro en sí mismo (el otro está muerto y nada puede salvarlo de esa muerte, ni nadie puede salvarnos a nosotros de ella), ni la simple inclusión de una fantasía narcisista en una subjetividad cerrada en sí misma o aun idéntica a sí misma (Derrida, 1988: 44/34).

Es por ello que Derrida señala que en esta memoria acongojada, adviene el otro. A partir de allí, la memoria es aconteciente, propiciante para la venida del otro que no puede ser incluido en la mismidad en el modo de la fagocitación (y de su consecuente neutralización de dicha alteridad) sino en la convivencia la mismidad, constituyéndola y tornándola ajena en una dinámica que, al no poder cerrarse sobre sí, impide la identidad. Más aun: la muerte del otro, esa muerte del otro en "mí", es, en el fondo, la única muerte nombrada en el sintagma "mi muerte", con todas las consecuencias que se puedan sacar de ello (Derrida, 1996: 318/123).

La afirmación de una pluralidad de memorias indica la imposibilidad de establecer un duelo con el otro, una fagocitación del otro en la mismidad en términos de la consolidación de un recuerdo único, acabado, propio. La presencia del otro en mí constituye la instancia de un duelo infinito, que se presenta en la modalidad de memorias que efectúan un provenir desde el pasado, a través de un presente que no puede distinguirse del pasado y el futuro sin devenir atemporal. Es por ello que, Mémoires: Pour Paulde Man, es el texto que manifiesta la presencia del otro que irrumpe en mí, que mediante el pasado, a partir de recuerdos no establecidos ni definitivos, interviene en un porvenir:

Esta finitud sólo puede cobrar esa forma mediante el vestigio del otro en nosotros, la irreductible presencia del otro; en otras palabras, simplemente la huella [trace], que es siempre la huella del otro, la finitud de la memoria, y así el abordaje o remembranza del futuro. Si hay una finitud de la memoria es porque hay algo del otro, y de la memoria como memoria del otro, que viene desde el otro y retorna al otro. Desafía toda totalización, y nos dirige a una escena de alegoría, a una ficción de prosopopeya, es decir, a tropologías del duelo: a la memoria del duelo, y al duelo por la memoria (Derrida, 1988: 49-50/40).
2. La figura del duelo imposible se encuentra en completa concordancia con los desarrollos de Torok y Abraham (1976). Por motivos de claridad expositiva no nos detendremos en el concepto de "cripta" en el cuerpo de nuestro trabajo. Sin embargo, quizás podamos decir aquí algunas cosas al respecto. En primer lugar, la noción de cripta resulta interesante para pensar la temática del duelo porque representa en cierto sentido el desdibujamiento o la reformulación de ciertas dinámicas (o al menos en la explicación de ciertas dinámicas) como sucede fundamentalmente en el caso del duelo. La noción de cripta transforma la relación entre "incorporación" e "introyección" mostrando cómo es posible la incorporación sin introyección, es decir, sin la redireccionalidad de la libido por parte del yo. De esta manera, quedaría un objeto, o cierta existencia diferente del yo en la mismidad que no podría ser reabsorbida en una dinámica de duelo por su carácter de ilocalizable ("La crypte garde un lieu introuvable por cause", J. Derrida, "Fors", Torok y Abraham 1976: 10), y que desafía a las localizaciones tópicas psíquicas, a su arquitectura: "La crypte est toujours une intériorisation, une inclusion plutôt en vue de compris, mais comme c'est une inclusion parasitaire, un dedans hétérogèn à l'intérior du Moi, exclu de l'espace d'introyjection génerale où il prend violemment place, le for cryptique entretient dans la répétition le conflit mortel qu'il est impuissant à résoudre". Torok y Abraham (1976:15). 
3. "En Heidegger, la relación ética, el Miteinandersein, estar-con-otro, no es más que un momento de nuestra presencia en el mundo. No ocupa el lugar central. Mit es siempre estar al lado de..., no es la apertura al Rostro, es zusammensein, quizás zusammenmarschieren" Lévinas (2001: 142).

4. Para analizar la espectralidadbenjaminiana en los textos derrideanos cf. Blanco (2015: 347-369).
El duelo, entonces, es duelo infinito, imposible, que nos insta a aceptar ese lugar ya ocupado por la alteridad, un lugar que se manifiesta no-lugar (dado que si no sería un otro identificable) y que, no obstante, exige una rotunda afirmación. Aceptar que el duelo sea duelo infinito es afirmar la presencia de lo otro, anterior a mí y, sin embargo, irreductible, desconocida y muchas veces, sin posibilidad de ser comprendida. El duelo imposible es la figura del respeto al otro que se manifiesta de forma eminente, es la afirmación que antecede a cualquier pretensión de identificación de un otro, debido a su carácter de existencia que continuamente se sustrae.

El duelo posible sólo puede pensarse a partir de la memoria en tanto interiorización, reduciendo al otro a la esfera de la mismidad. Sin embargo, aun en el intento de un duelo posible, comprobamos que la alteridad se nos escapa, que este ilusorio sentimiento de seguridad sólo es aparente, ya que "el otro resiste la clausura de nuestra memoria interiorizante" (Derrida, 1988: 50/40). La alteridad, no obstante, no es simplemente una pura exterioridad, la consecuencia de ello es la imposibilidad de localización del otro, pero también, de la alteración del sí-mismo que ya muriendo, deja de ser considerado como el vivo frente al muerto. Mi vida es sobrevida, finitud que:

Que el Otro no puede ser absolutamente exterior a lo mismo sin dejar de ser otro, y que, por consiguiente, lo mismo no es una totalidad cerrada sobre sí, una identidad que juega consigo, con la mera apariencia de la alteridad, dentro de lo que Lévinas llama la economía, el trabajo, la historia ¿Cómo podría haber un "juego de lo Mismo" si la alteridad misma no estuviera ya dentro de lo Mismo, con un sentido de la inclusión que la expresión dentro de sin duda tradicional? (Derrida, 1996: 318/123)

Otro, entonces, no significa total ajenidad sino la presencia de la alteridad en la mismidad que se resiste a ser reabsorbida en el intento subjetivo de reapropiación o identificación. Por el contrario, la alteridad es constitutiva de la subjetividad siendo la presencia de la alteridad una condición inescindible de toda subjetividad. En este sentido ser es siempre ser-con, como de algún modo ya lo había adelantado Heidegger a partir del existenciario del Mit-Sein que todo Dasein desde siempre es. Sin embargo, a diferencia de Heidegger, que todavía sostiene cierta simetría en el Mit-Dasein, el ser-con derrideano retoma el legado levinasiano postulando una asimetría inevitable con el otro, en la medida en que el otro siempre es el lugar de lo diferente, el otro no es el tú, sino un tercero. ${ }^{3}$ Y esta disimetría con el espectro nos conduce, quizás a modo de corolario de esta sección, al posicionamiento derrideano filosófico, central a nuestro juicio, a saber, que la tarea filosófica es una tarea de herencia. Herencia crítica, acontecimental, imposible.

La idea de espectro vinculada a la noción de duelo imposible que leemos en las páginas de Espectros de Marx quizás pueda ser comprendida en consonancia con la idea benjaminiana de pasado tematizada en Sobre el concepto de historia. ${ }^{4}$ En ese sentido, desde la perspectiva histórico-política, Benjamin -y a nuestro juicio Derrida a partir del empleo de la categoría que aquí examinamos- reflexiona acerca de cómo se articula el pasado en la experiencia política de los tiempos actuales. El espectro parece así remitirnos a un presente asediado por una figura peculiar del pasado. Un pasado que insiste en quedarse, abierto, resistente a la clausura. En contraposición a ello, el pasado del melancólico es aquel que sólo puede mirarse hacia atrás, añorando lo que ya no puede volver a ser, pero que alguna vez aconteció. El pasado pendiente, trunco en cuanto puede ser presente, las voces de aquellos vencidos se manifiestan en el presente bajo la modalidad de cierta latencia, delimitando el pasado como diferencia inherente al presente mismo y que, por su misma condición de inconcluso, le compete aún hoy a nuestros tiempos. 
IV. El volumen compilado por Michael Sprinker, Demarcaciones espectrales, reúne una serie de artículos, fundamentalmente del ambiente intelectual marxista contemporáneo. Diversas son las discusiones que estos artículos presentan, en un recorrido que alberga dentro de sí desde una manifiesta indignación por el vínculo que el filósofo franco-argelino presenta entre la deconstrucción y el marxismo, apelando tanto a una revisión de ciertas tesis de la deconstrucción y evaluando así las posibles cercanías entre esta filosofía y la marxista; así como también insistiendo por momentos en la falta de una visión adecuada de las interpretaciones del marxismo contemporáneo. Podemos hallar entre las páginas de este volumen un análisis detallado de la interpretación y, por ende, de cierta recepción del marxismo en la actualidad, constatando así la relevancia del discurso derrideano en estos tiempos, consecuencia de su posicionamiento central en el ámbito académico e intelectual de Europa y los Estados Unidos.

Las nociones que toman centro en la discusión de estos artículos representan en gran medida los pilares de la filosofía derrideana tardía. Entre ellos, podemos mencionar la idea una justicia irreductible al derecho y la de espectro (como puede observarse mirando solamente el título de la obra derrideana); así como también la de "materialismo" de origen marxista, que es abordada en este volumen a través de un tratamiento oblicuo en la filosofía derrideana.

Así, el artículo de Toni Negri que inicia el volumen, "La sonrisa del espectro", señala cierta continuidad de la deconstrucción con el marxismo en tanto tarea desmistificadora:

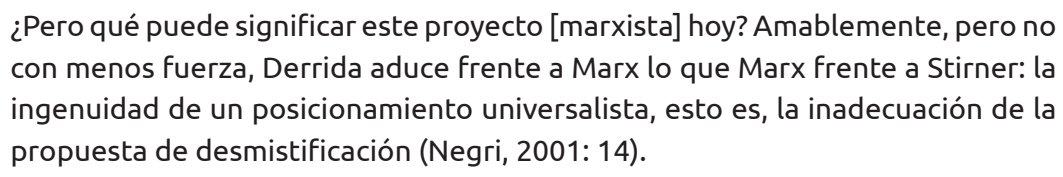

Este paso indicado por Negri estaría dado por la imposibilidad de remitir en "nuestros días" a cierto valor de uso y subjetividad en tanto componentes independientes del carácter espectral del capital. Como sabemos, Negri junto con Hardt han ido elaborando a partir de Imperio (2003) la categoría de "trabajo inmaterial" para dar cuenta de cierta mutación del paradigma del trabajo. En este sentido, la deconstrucción parecería aportar, desde una cierta línea de análisis, un acompañamiento de los procesos ya en marcha del capitalismo contemporáneo y de sus consecuentes transformaciones de la teoría del valor marxiana, que ya no podrían pensarse desde una concepción del tiempo como operador de la medida del valor (quizás the time is out of joint), así como tampoco desde el valor de uso como un referente real, último, perteneciente a las metafísicas de lo propio que la filosofía derridiana ha sabido combatir.

Sin embargo, el camino de la deconstrucción en compañía de Negri llega a su final, cuando el filósofo italiano confunde los "espectros de Marx" con los "espectros del capital", confundiendo así el objeto del duelo derridiano. Si bien es cierto que Derrida tematiza el carácter espectral, e incluso virtual, del capital, el duelo -imposible por cierto- que el libro parece, o bien proponer, o bien revelar como marca contemporánea de occidente, es el duelo imposible del marxismo, de cierto marxismo. Así, la deconstrucción de Espectros de Marx se presenta en parte como el gesto imposible de establecer un duelo, un duelo quizás dislocado con cierto marxismo en tanto labor desmistificadora.

Como señalamos previamente, la idea de espectro vinculada a la noción de duelo imposible que leemos en las páginas de Espectros de Marx quizás pueda ser comprendida en consonancia con la idea benjaminiana de pasado tematizada en Sobre el concepto de historia. En ese sentido, desde la perspectiva histórico-política, Benjamin 
5. "La huella nos permite aferrar la idea de la irreductibilidad de la escritura al habla y del habla a un pensamiento inmaterial, la noción de que por muy lejos que nos remontemos nunca llegamos a un momento de pura idealidad, el momento de la idea anterior a su materialización como voz (cuya irreductibilidad al pensamiento le confiere el estatuto de un tipo de escritura." Althusser (1988: 88). Según Althusser, la huella nos permite aferrar la idea de la irreductibilidad de la escritura al habla y del habla a un pensamiento inmaterial. Nunca llegamos a un momento de pura idealidad, el momento de la idea anterior a su materialización como voz (cuya irreductibilidad al pensamiento le confiere el estatuto de un tipo de escritura. Para analizar las cercanías entre Althusser y Derrida a la luz del concepto de 'huella' cf. Baring (2011: 288 y ss.). -y a nuestro juicio Derrida a partir del empleo de la categoría que aquí examinamos- reflexiona acerca de cómo se articula el pasado en la experiencia política de los tiempos actuales. El espectro parece así remitirnos a un presente asediado por una figura peculiar del pasado. Un pasado que insiste en quedarse, abierto, resistente a la clausura. En contraposición a ello, el pasado del melancólico es aquel que sólo puede mirarse hacia atrás, añorando lo que ya no puede volver a ser, pero que alguna vez aconteció. El pasado pendiente, trunco en cuanto puede ser presente, las voces de aquellos vencidos se manifiestan en el presente bajo la modalidad de cierta latencia, delimitando el pasado como diferencia inherente al presente mismo y que, por su misma condición de inconcluso, le compete aún hoy a nuestros tiempos. El espectro es la inconclusión de nuestro pasado. La latencia de algo que no pudo ser y que, sin embargo, nos constituye en tanto marca: nada más alejado de una concepción nostálgica, aun cuando el espectro de nuestro duelo coincidiese con el que Negri parece postular en su artículo.

Así, contrariamente a lo que piensa Negri, hoy, con los fantasmas marxianos algo podemos hacer: podemos reconocerlos como marcas constitutivas de la política de occidente, como una guía hacia nuevas vías de acción desde aquellas voces de los vencidos, para decirlo con Benjamin, que constituyen una tradición discontinua (out of joint, quizás) necesaria tanto para no repetir aquellos errores de los que no nos vanagloriamos, como para afinar las estrategias hacia lo que queramos conseguir.

En su artículo "Espíritus armados y desarmados: los Espectros de Marx de Derrida", Warren Montag señala el presunto tránsito de la filosofía derrideana desde un cierto tipo de materialismo hacia una filosofía de corte idealista, a partir de la formulación de una idea de justicia con tintes cuasi trascendentales.

Algunos autores intérpretes de Derrida, al igual que Montag, sostienen que en la filosofía derrideana puede observarse un cierto viraje a partir de la introducción de temáticas tales como la justicia, la democracia por venir, etc. Si bien se puede constatar una continuidad entre dichos desarrollos (la temática de la deconstrucción, la cuestión de la différance, etc.) -continuidad que, por otra parte, Derrida insiste en señalar, sobre todo en lo que concierne a la presencia de la problemática política desde sus primeras obras-, no obstante, existen algunas tesis que sostienen que el paso del primer al segundo momento de la filosofía derrideana podría caracterizarse como el paso de una filosofía fundamentalmente materialista, sobre todo a través de las interpretaciones de Althusser ${ }^{5}$ acerca del concepto de "huella", a un segundo momento fundamentalmente idealista a partir de una noción como la de justicia, completamente separada del ámbito de lo posibleefectivo, no deconstruible y, por tanto, ajena a las condiciones materiales de lo jurídico:

\footnotetext{
Mientras Derrida, en su texto Fuerza de ley, parece considerar la justicia fuera del derecho y el Estado (inclusive de un derecho y un Estado aún por realizar) más allá de la fuerza (...) y, por tanto, dotándola de una existencia espiritual indeconstruible, Marx, siguiendo el espíritu de Spinoza, hablaba de un espectro que en ningún caso podía comprenderse como "aquello que uno imagina, aquello que uno cree ver y que proyecta: en una pantalla imaginaria, allí donde no hay nada que ver (Montag, 2002: 88-89).
}

Otro elemento que cabe mencionar aquí es la filiación que el mismo Derrida en Positions, establece entre su filosofía y una cierta concepción del materialismo. Esta concepción se pondría en evidencia fundamentalmente a través de la crítica del filósofo francés al concepto de "logocentrismo" como idealismo "contra la autoridad del sentido, como significado trascendental o como telos": 


\begin{abstract}
El logocentrismo también es, fundamentalmente, un idealismo. Es la matriz del idealismo. El idealismo es su representación más directa, su fuerza más dominante. Y el desmonte del logocentrismo es simultáneamente -a fortioriuna deconstrucción del idealismo o del espiritualismo en todas sus variantes. Verdaderamente aquí no se trata de "borrar" la "lucha" contra el idealismo. Ahora que, naturalmente, el logocentrismo es un concepto más amplio que el de idealismo, al que sirve de base desbordante. Más amplio también que el de fonocentrismo. Constituye un sistema de predicados, ciertos de los cuales siempre pueden encontrarse en las filosofías que se dicen no-idealistas, o sea anti-idealistas. El manejo del concepto de logocentrismo es pues delicado y a veces inquietante (Derrida, 1977: 118).
\end{abstract}

Retomando entonces la distinción de Montag, la filosofía derrideana habría sufrido un viraje pasando de cierto materialismo heterodoxo a una suerte de idealismo. Todas las aporías presentes en la filosofía derrideana sufrirían de esta suerte: la justicia y el derecho, la hospitalidad absoluta y las leyes condicionales de la hospitalidad, etc. Y este "paso idealista" de la filosofía derrideana imposibilitaría pensar a la deconstrucción como un pensamiento emparentado con el marxismo. ${ }^{6}$ Frente a una cercanía inicial de la posición derrideana a un materialismo aleatorio, del encuentro y de la contingencia, Derrida habría dado el paso idealista a la luz de sus nociones de lo incondicional. ${ }^{7}$ Siguiendo esta línea, autores como Balkin, han interpretado la noción de justicia como una idea de carácter trascendente, dando lugar a una "deconstrucción trascendental", acercando la idea de justicia a un "valor trascendental" que podría ya observarse en los diálogos platónicos tardíos (Balkin, 1994). Sin entrar en discusión con esta tesis -que adopta una posición ciertamente alejada del espíritu de la filosofía derrideana que queremos aquí retomar- ${ }^{8}$ nos parece interesante pensar la cuestión de este presunto carácter idealista del pensamiento derrideano.

Contra esta tesis y aun sosteniendo la evidencia de un cambio de enfoque en la filosofía derrideana, nuestra argumentación defenderá la posición contraria, más aún, la filosofía derrideana nunca ha dejado de ser una filosofía de carácter materialista (al menos en un sentido amplio). Evidentemente, la lectura de estos autores supone un hiato de las aporías derrideanas, hiato que, a nuestro juicio es posible articular a la luz de la noción de espectralidad. ${ }^{?}$

La forma de contacto entre estos dos ámbitos es el espectro. A nuestro juicio, los tratamientos acerca de un posible materialismo (de la persistencia de un tipo de materialismo) en el pensamiento derrideano tardío (y en el caso de que tenga sentido esta distinción) se hace posible desde la noción misma de espectro. Fruto de una comprensión errónea de dicho término, algunos autores plantean que también la noción de espectralidad supondría una aprioricidad de lo ideal por sobre lo material. Ahora bien, es importante en esta elucidación que intentamos delimitar aquí en relación a la categoría de espectro, establecer una distinción entre ella y la de espíritu. Porque el espectro, lejos de representar la espiritualización o autonomización del espíritu, agrega una dimensión heterogénea a partir de su devenir-carne. En última instancia, el espíritu deviene espectro en la medida en que se hace cuerpo. Pero este cuerpo, lejos de presentarse como una pura presencia, desafía los modos fenomenológicos del darse:

El momento fantasmal le sobreviene [le moment fantomal lui survient] y le añade una dimensión suplementaria, un simulacro, una alienación o una expropiación más. A saber, ¡un cuerpo! ¡Una carne (Leib)! Pues no hay fantasma, no hay nunca devenir-espectro del espíritu sin, al menos, una apariencia de carne, en un espacio de visibilidad invisible, como des-aparecer de una aparición. Para que haya fantasma, es preciso un retorno al cuerpo, pero a un cuerpo más abstracto que nunca (Derrida, 1995: 26).
6. Recordemos la continuidad que Derrida en Espectros de Marx establece entre su filosofía y el marxismo a partir de la capacidad crítica de la deconstrucción, pero también la posibilidad de encontrar un pensamiento del acontecimiento, una manera diferente de pensar la temporalidad y, con ello, otro pensamiento de la historicidad. 7. Cabe destacar que la lectura de Montag sobre la distinción althusseriana resulta ciertamente algo compleja a la hora de trazar una lectura sobre este desplazamiento derrideano. Althusser elabora la concepción de un "materialismo aleatorio" apelando a la noción epicúrea de clinamen para romper con lo que él considera las filosofías del idealismo presentes en el marxismo, a saber, aquellas que apelan a la Razón o a una Causa Primera como origen del mundo. Althusser(1988: 31). Los materialismos de Marx, Engels y Lenin serían idealismos disfrazados en la medida en que se apoyarían en una tradición racionalista de la necesidad y la teleología. Althusser (1988: 33). En última instancia, la crítica althusseriana encontraría su blanco en la cuestión de la dialéctica como fuente de la teleología: "En este sentido, no cabe hablar de "leyes" de la dialéctica, de la misma manera que no cabe hablar de "leyes" de la historia". (Althusser 1988: 22). Como podemos observar, el caso derrideano no se ajusta de manera evidente a la delimitación althusseriana del idealismo.

8. Balkin piensa la idea de justicia derrideana como una suerte de valor de carácter universal, junto con otros valores que residen en el alma humana. El problema que encontramos en principio en esta interpretación es que caracterizar a la justicia como un valor universal parece entrar en conflicto con la temática de la diferencia tan presente en el filósofo francés. Postular la universalidad de la idea de justicia como un valor humano (aun cuando ésta necesite de la mediación de una cultura determinada) sería establecer en cierto modo una igualdad entre los hombres, postulación que en principio no resulta tan fácil de adjudicar a una filosofía como la derrideana, que siempre ha enfatizado como un valor fundamental la diferencia y la asimetría como condición de todo contacto con el otro, no habiendo elementos para establecer una igualación que se presente a priori, sino que, en todo caso, toda igualación representaría en cierto sentido un ejercicio de violencia en tanto neutralización de la diferencia misma.

9. Para un análisis minucioso de la temática de la aporía en el pensamiento derrideano cf. Gasché (2002: 103-121). “Ce passage montre clairement que l'aporie, tout comme l'impossibilité concomitante de la résoudre dialectiquement, loin de représenter une impasse, est considérée au contraire comme une chance, ou même comme l'occasion à saisir ("peut-être») pour la philosophie elle même. Au lieu de constituer un obstacle pour la pensée, l'insolubilité des apories devient la condition de possibilité d'une rencontre avec une forme de pensée qui se distingue absolument de toute autre, la pensée philosophique". Gasché (2002: 106). 
Podemos tomar por caso la aporía entre la justicia y el derecho y decir que la justicia habita el derecho en forma espectral, dislocándolo, desde adentro (un adentro y afuera que no son deslindables o que no responden a la modalidad de lo posible-efectivo, resultando lo imposible inmune frente a dichas fronteras). En este sentido, entonces, creemos que se puede pensar a la justicia derrideana como un movimiento interno a los procesos mismos de producción de lo jurídico, pero esta interioridad, lejos de representar un existir presente, se manifiesta bajo una forma de existencia peculiar que intentaremos ir caracterizando pormenorizadamente: "Por el contrario, el espectro al que se enfrentaban 'los poderes de la vieja Europa' sin duda alguna habitaba una forma corpórea, a la que no podríamos decir que preexistiera" (Derrida, 1993: 134/94).

Podríamos decir que la misma operación que Derrida realiza con Marx -con alguno de sus espectros- es la que nosotros podemos intentar pensar con la idea de justicia derrideana. Si el espíritu del marxismo tiene cierta eficacia es porque habita en las relaciones mismas de producción, en su conflictividad, en los movimientos de lucha, etc. Del mismo modo, la idea de justicia posee una eficacia en el derecho en tanto es inmanente a él. Y justamente porque habita en el derecho, no puede pensarse como una suerte de ideal regulativo que tiende hacia una teleología, en tanto dicha concepción delata una comprensión errada del estatuto ontológico mismo de la idea de justicia. Pedirle a la justicia un plan o programa mediante el cual el derecho se realice en sus formas jurídicas es esperar algo absurdo, es esperar que la justicia responda a una lógica de lo posible (pensando además, que lo finito puede realizarse en lo infinito). Pero la justicia pertenece al plano de lo imposible y, por ello, tiene la ventaja de poder rebasar (o, para decirlo con Heidegger "trascender") las condiciones de posibilidad que de hecho parece arrojar lo real (abriendo así nuevas condiciones de posibilidad, imposibles hasta ese momento). No obstante, esta virtud parece trastocar en desventaja en la medida en que no brinda un programa, una metodología, una estrategia de aplicabilidad al derecho. Pensar que la única relación entre justicia y derecho pueda ser la de regulatividad significaría pensar el vínculo entre justicia y derecho en el plano de la presencia, dejando fuera otras posibilidades de existencia como hemos intentado mostrar a partir de la concepción de espectro, de la cual haremos usufructo a lo largo de trabajo para pensar la articulación entre lo imposible y lo posible.

Considerado desde el plano de la presencia, parecería ser que no hay relación posible entre justicia y derecho, en la medida en que la justicia no parece presentar los elementos de una noción que respondiese al propósito de limitar y postular de fines, postulando un hiato entre justicia y derecho (con la consecuente concepción de la idea de justicia como deudora de una filosofía idealista). La justicia no mantiene una relación de fundamentación con el derecho. Por otra parte, quizás sea interesante mirar desde otra óptica a la justicia, diferente de la que empleamos al considerar a lo jurídico.

Abandonando el intento entonces de pensar a la justicia bajo las mismas exigencias bajo las cuales pensamos al derecho, quizás sería más fructífero considerar que la relación entre lo heterogéneo no puede pensarse ni postularse como la relación entre lo igual. Es entonces en este sentido que, siendo justicia y derecho ámbitos heterogéneos (imposible y posible-efectivo), podemos iniciar una reflexión en la cual nos encontremos con nuevas formas de articulación entre ambas partes, sin por ello abandonar la pretensión de "cierto materialismo" de la filosofía de la deconstrucción. Y esta posibilidad estará dada por la figura del espectro, figura que (re) aparecerá una y otra vez al servicio de un cierto materialismo, aquel que toda crítica de lo trascendental exige. Porque es el espectro el que nos permitirá pensar esa mesianicidad derrideana como estructura general de la experiencia, de una experiencia que sólo sostiene el vocablo en nombre de su herencia, porque la lógica del doble golpe mesiánico, nos permitirá pensar algo más que una ruptura, nos permitirá pensar la ley como ley del otro. 
Contra la tesis de Montag, y aun sosteniendo la evidencia de un cambio de enfoque en la filosofía derrideana, nuestra argumentación defiende una posición contraria: la filosofía derrideana nunca ha dejado de ser una filosofía de carácter materialista (al menos en un sentido amplio). Si la justicia pertenece a lo que Derrida alude como el ámbito de lo imposible, el derecho, por su parte, puede ser pensado en el ámbito de lo posibleefectivo: un habitar subterráneo que, entre sus manifestaciones fenoménicas de aquella fenomenología de lo inaparente, sería justamente la deconstrucción de lo jurídico. La modalidad espectral del asedio permite considerar un contacto en el plano de lo metafísico que, claramente, nos permitiría emplearlo en la discusión aquí en cuestión, referida a la idealidad del pensamiento de la justicia derrideano.

Si lo imposible y lo posible no fueran ámbitos conectados de algún modo entre sí, lo imposible entonces no tendría nunca eficacia en lo real y permanecería solamente como una mera postulación, impotente para pensar nuestra historia de lo jurídico. Entre Hegel y Marx, entre un universal concreto totalizante y el infinito malo de Kant, aquel que no se realiza en lo finito y queda asintóticamente esperado. Es por ello que, a nuestro juicio, la figura del espectro permitiría una articulación no dialéctica de las aporías derrideanas planteadas en los últimos años: justicia-derecho, etc. y con ello, la posibilidad de pensar nuevas articulaciones que no se cierren sobre un horizonte dialéctico totalizador.

V. En el presente trabajo hemos intentado delimitar algunos de los usos de la noción de espectralidad derrideana en torno a la crítica de la metafísica y de su noción de existencia como presencia, de la deconstrucción del umbral entre la vida y la muerte, a la luz de la temática del duelo infinito y de lo imposible, considerado ya no como aquello que se enfrenta a lo posible, sino en una compleja articulación de lo aporético. Porque la espectralidad se ofrece como una manera de articulación no dialéctica de las aporías, articulación que mantiene sus diferendos extensión sin por ello, reducirlos uno a otro.

En este sentido, queríamos por último destacar, la figura del espectro opera en la filosofía derrideana como deconstrucción de cierta herencia del espíritu ${ }^{10}$ y con ello, de una concepción de la historia y la política idealista. Es por ello que la historia no es realización, sino historicidad, pero historicidad alterada, acontecimental, difiriente. En este sentido, remite a la eficacia de lo imposible en lo posible, como un nuevo espacio de apertura de la ontología.

Los arribantes, los espectros, son la posibilidad de apertura de las totalidades, del sujeto, de la comunidad política. Ellos marcan la fase mesiánica de todo proceso histórico-político, rompiendo el paradigma epistemológico moderno de la constatación subjetiva, para consignarnos a la espera de la interpelación. Los espectros franquean los umbrales, llegan de noche, como ese ladrón inadvertido. Comenzar por la finitud, por la grieta. "Necesitar tiempo significa: no poder anticipar nada, tener que esperarlo todo, depender del otro para lo más propio" (Rosenzweig, 1976: 438/34). Una negatividad trunca que horada los caminos afianzados del inmanentismo secular. Las "miles de nadas" de la totalidad quebrada que impiden el despliegue teleológico-idealista y nos enfrentan con el desarraigo de una espera sin horizonte, como responsabilidad infinita ante el otro.
10. Por motivos de extensión, no abordaremos aquí esta cuestión, pero cabe destacar un texto temprano que resulta pertinente para abordar dicha deconstrucción, a saber, "Del espíritu", allí donde Derrida critica el uso heideggeriano del Geist en su remisión a la lógica de lo Uno y de la Versammlung, esto es, de la reunión. 


\section{Q Bibliografía}

"Althusser, L. (1988). Filosofía y marxismo. México: Siglo XXI.

" Balkin, J. M. (1994). Trascendental deconstruction, trascendent justice. Michigan Law Review, vol. 92, nº 5.

» Baring, E. (2011). The Young Derrida and French Philosophy. Cambridge: Cambridge University Press.

» Benjamin, W. (2009). Sobre el concepto de historia. En Estética y política. Walter Benjamin (Trad. Tomas Joaquín Bartoletti y Julián Fava). Buenos Aires: Las Cuarenta.

» Blanco, B. (2015). Espectros de Derrida. En Bórquez, Z. (Comp.). Fenomenología, Firma, Traducción. Santiago de Chile: Pólvora Editorial.

» Cragnolini, M. B. (2007). Derrida, un pensador del resto. Buenos Aires: La Cebra.

»De Peretti, C. (Ed.) (2003). Espectrografías (Desde Marx y Derrida). Madrid: Trotta.

"Derrida, J. (1996). Apories. Mourir -s'attendre «aux limites de la verité». Paris: Galilée. (1998) Aporías, Morir-esperarse (en) 'los límites de la verdad' (Trad. Cristina de Peretti). Barcelona: Paidós.

»Derrida, J. (1994a). Force de loi. Le «Fondement mystique de l'autorité». Paris: Galilée, 1994. Fuerza de ley (1997). Trad. Adolfo Barbera y Patricio Peñalver. Madrid: Tecnos.

» Derrida, J. (1988). Mémoires, Pour Paul de Man. Paris: Galilée. Memorias para Paul de Man (1998). Trad. C. Gardini. Barcelona: Gedisa.

»Derrida, J. (1994b). Politiques de l'amitié suivi de L'oreille de Heidegger. Paris: Galilée. Políticas de la Amistad seguido de El oído de Heidegger(1998).Trad. P. Peñalver. Madrid: Trotta.

»Derrida, J. (1977). Posiciones. Madrid: Pre-textos.

"Derrida, J. (1993). Spectres de Marx. L'État de la dette, le travail du deuil et la nouvelle Internationale.Paris: Galilée. Espectros de Marx El estado de la deuda, el trabajo del duelo y la nueva internacional (1995).Trad. José Miguel Alarcón y Cristina De Peretti. Madrid: Trotta.

"Freud, S. (1997). Duelo y melancolía. Obras completas, vol.15. Buenos Aires: Losada.

» Gasché, R. (2002). L'expérience aporétique aux origines de la pensée. Platon, Heidegger, Derrida. Études françaises, vol. 38, n¹-2, $103-121$.

» Lévinas, E. (2001). Entre Nosotros. Ensayos para pensar en otro. Valencia: Pre-Textos.

» Montag, W. (2002). Espíritus desarmados. Los espectros de Marx de Derrida.

»Sprinker, M. (Ed.). Demarcaciones espectrales En torno a Espectros de Marx de Jacques Derrida. Madrid: Akal.

» Negri, A. (2002). La sonrisa del espectro. En Sprinker, M. (Ed.). Demarcaciones espectrales En torno a Espectros de Marx de Jacques Derrida. Madrid: Akal.

»Negri y Hardt (2003). Imperio (Trad. Alcira Bixio). Buenos Aires: Paidós. 
»Rosenzweig, F. (1976). Das neues Denken. Einige nachträgliche Bemerkungen zum "Stern der Erlösung". Gesammelte Schriften, B.III, Den Haag. El nuevo pensamiento (2005), trad. Ángel García-Maturano. Buenos Aires: Adriana Hidalgo editora.

» Torok, M. y Abraham, T. (1976). Crytonymie. Le verbier de l'homme aux loups. Paris: Aubier Flammarion. 
